\title{
Agile Knowledge Supply Chain for Emergency Decision-Making Support
}

\author{
Qingquan Wang and Lili Rong \\ Institute of Systems Engineering, Dalian University of Technology, 116024 Dalian, China \\ dlwqq@hotmail.com, llrong@dlut.edu.cn
}

\begin{abstract}
Facing complex and changing emergencies decision makers need to obtain sufficient background knowledge to make effective decisions. We outline the characteristics of requirements for decision-making around knowledge sources, agility and the nature of knowledge products in quick responses to emergencies. We characterize the process of knowledge management in emergencies as quotation, manufacture and supply of a special product -- Emergency Knowledge Product. From the point of view of achieving agility, we draw on the operational mechanism of the Agile Supply Chain (ASC) to construct Agile Knowledge Supply Chain (AKSC), a first in this paper. According to Similarities between ASC and AKSC, here we depict definition and architecture of AKSC. AKSC can explore a new approach to knowledge-based quick responses in the emergency decision-making support.
\end{abstract}

Keywords: Emergency Decision-Making, Knowledge Product, Knowledge management Agility, Agile Knowledge Supply Chain.

\section{Introduction}

Nowadays, humans are threatened by various unexpected disasters which include all kinds of terror attacks, epidemics, hurricanes, tsunamis, earthquakes, air crashes, collective food poisoning and industrial accidents. With increasing technology, population and deterioration of the environment, losses of such disasters are increasing exponentially. An outbreak of these disasters causes immeasurable losses in lives and property, like the 911 terror attack, SARS, the bird flu, the Indian Ocean tsunami, the Katrina hurricane, and the Pakistan earthquake. Quick and effective decision- making is crucial in emergency responses [1], and is closely related to background knowledge of circumstances and experiences [2].

In the last decade, Emergency Decision Support Systems (EDSS) have gradually introduced and integrated the technologies of knowledge management. For examples, advanced knowledge models to support environmental emergency management in [3], aggregation of the knowledge of geographically separate experts in [4], the EDSS raised in [5], the expert system developed for knowledge acquisition of chemical incidents [6], the agent-based environmental emergency knowledge system in [7]. The knowledge-based EDSS is still in its primary stage, but the maturation of knowledge-based technologies is facilitating this enterprise. [5]. 
The speed and quality of background knowledge are key factors in quick-response emergency decision-making. Mendonca deems that speed of response and quality of knowledge is crucial factors for effective emergency response [4]. And Viviane emphasized time pressure in Collaborative Emergency Responses, described a system which aims at storing and disseminating contextual knowledge to an emergency [8]. Therefore, there are the problems of agility in emergency responses.

Agility of knowledge system is a new research subject in the knowledge management field. Some researchers have started focusing attention on the agility of knowledge system; for example, KWM, in improving the agility of knowledge management [9], agile knowledge sharing [10], agile knowledge workflow [11], agile knowledge engineering methodology, RapidOWL [12], and project SAKE launched by European Community [13]. Agility is much more prominent in the knowledge-based EDSS, especially acquisition of background knowledge, and it is an important indicator for evaluating the aided effectiveness of decision-making background knowledge in relieving time pressure.

The agile manufacturing field gives us a hint that the Agile Supply Chain (ASC) can adjust itself to fit the continuous changes in market demands. A Supply Chain is a loosely related group of companies formed to enable collaboration in achieving mutually agreed upon goals [14], and includes activities and processes to supply products or services to end-users. The concept of ASC was introduced by Stanford University. Researches of ASC mainly concentrate on virtual enterprises, information flow, Supply Chain reconstruction, etc. [15], [16]. From the point of view of the agility of providing background knowledge to the decision-maker, we outline the characteristics of requirements of decision-making and apply emergency knowledge management to the process of quotation, manufacture and supply of a special product. We draw on the operational mechanism of ASC to construct the Architecture of the Agile Knowledge Supply Chain (AKSC) for emergency decision-making support.

In this paper the requirements of emergency decision-making including knowledge resources, characteristics of knowledge requirements and product requirements, are introduced in section 2. In section 3, the nature of ASC, the definition of AKSC and their similarities are discussed. In section 4, we present AKSC architecture. Finally, a summary of this paper is given in section 5 .

\section{Requirements of Emergency Decision-Making}

\subsection{Requirements of Emergency Knowledge Sources}

"Knowledge is not the same as information. Knowledge is information that has been pared, shaped, interpreted, selected, and transformed"-- E. Feigenbaum.

Processing emergency raw information into knowledge is similar to processing raw materials into products. Knowledge processing has specific sources of information. In knowledge-based EDSS there are three main sources of 'raw material' information: emergency environments, contributing emergent incidents and emergency documentation, shown in figure 1. 


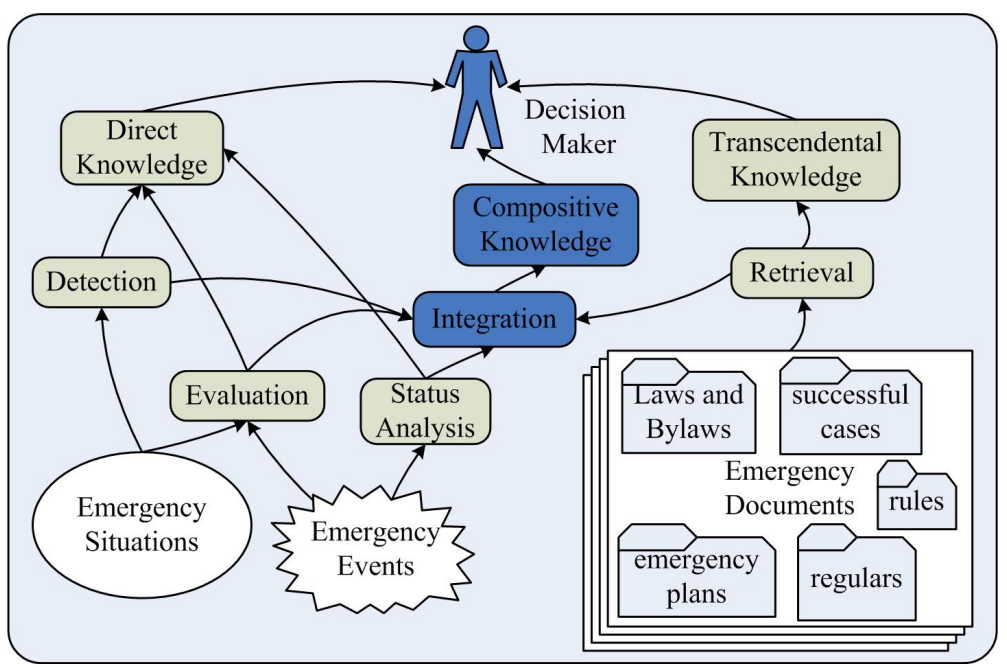

Fig. 1. Sources of Emergency Knowledge

Information materials usually come from emergency environmental monitoring and assessment, analysis and evaluation of emergent incidents, empirical information from emergency documentation, and the integration of them. They constitute respectively, direct knowledge, transcendental knowledge and integrated knowledge.

Direct knowledge and transcendental knowledge have a better application in the existing EDSS, but the most difficult thing is to integrate data, information and knowledge from various information sources [17]. Therefore, in knowledge-based emergency decision support we should not only provide the decision-makers with direct knowledge and transcendental knowledge, but also integrate them effectively to reduce the pressure on decision-makers for improved decision- making.

\subsection{Requirements of Agility of Knowledge Support}

"Knowledge should be presented understandably, simply, clearly"-- Z.T. Wang [18].

Knowledge in different applications requires different features. Such as generality, complexity and implicity are main features of knowledge in Knowledge Engineering.

In the process of quick emergency response, the knowledge decision-makers receive should be correct, complete, clear and simply described. In addition to these spatial characteristics emergency knowledge management also has characteristic temporal agility. Any loss of agility results in a loss of its original value to decisionmakers. Emergency knowledge management agility minimizes time required for processing of emergency knowledge in acquisition, representation and reasoning.

We can regard agility as a feature of emergency knowledge for comparison. Suppose that knowledge provided is transcendental knowledge from emergency documentation. The correctness and completeness of it can be verified and evaluated before the emerging event. The relationships between agility and other characteristics of emergency knowledge can be illustrated roughly through a cube in Figure 2. 


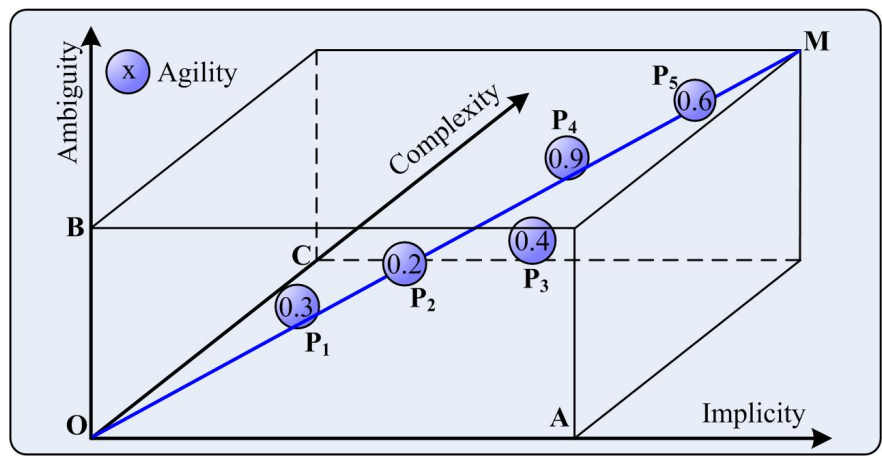

Fig. 2. Cube of Emergency Knowledge Features

With the exception of agility, the closer the points of knowledge are to $A$ the more implicit the emergency knowledge is; the closer to $B$, the more ambiguous; to $C$, the more complex. By the same token, the closer they are to point $O$, they are more explicit, precise and simple. Point $O$ can be expressed as (Explicit, Precise, Simple), and Point $M$ as (Implicit, Ambiguous, Complex). In other words, efficient decision-making support should provide explicit, precise and simply described emergency knowledge. The closer they are to origin $O$ in Figure 2 the more efficient they are.

However, in practical applications agility in decision-making support is usually the most critical factor, see figure 2. Among the knowledge points $\left\{P_{1}, P_{2}, P_{3}, P_{4}, P_{5}\right\}$, point $P_{4}($ Agility $=0.9)$ has the highest probability of being accepted as the most agile.

\subsection{Emergency Knowledge Features Required}

"Knowledge is a product of the human spirit, mediated by language." -- A. Sigel [19].

In response to a certain emergency, the emergency knowledge available for decision-makers often comes from different departments, various emergency documentation, diverse environments, or experience from similar cases. The acquisition of emergency knowledge involves the process of knowledge decomposition, matching and integration.

Knowledge and products have their respective characteristics. For example, products are usually tangible expendable exclusive, and have value; but knowledge is intangible, unquantifiable value, re-usable and share-able, as it is shown in figure 3 . However, in the knowledge management of emergency decision-making, there are notable similarities between product and knowledge, the intersection in Figure 3. They both are demand-driven, subject to supply and demand matching requirements, have their corresponding owners and transfer regularly from one to another, have their respective raw materials, structural characteristics and functions, can be decomposed and integrated, and are agile in generation and supply.

Therefore, in quick response emergency decision-making, the knowledge decisionmakers receive and use is a kind of product, Emergency Knowledge Product (EKP). EKP is a product processed from dispersed emergency information, and it can be said that the process of EKP is a special approach to knowledge representation. 


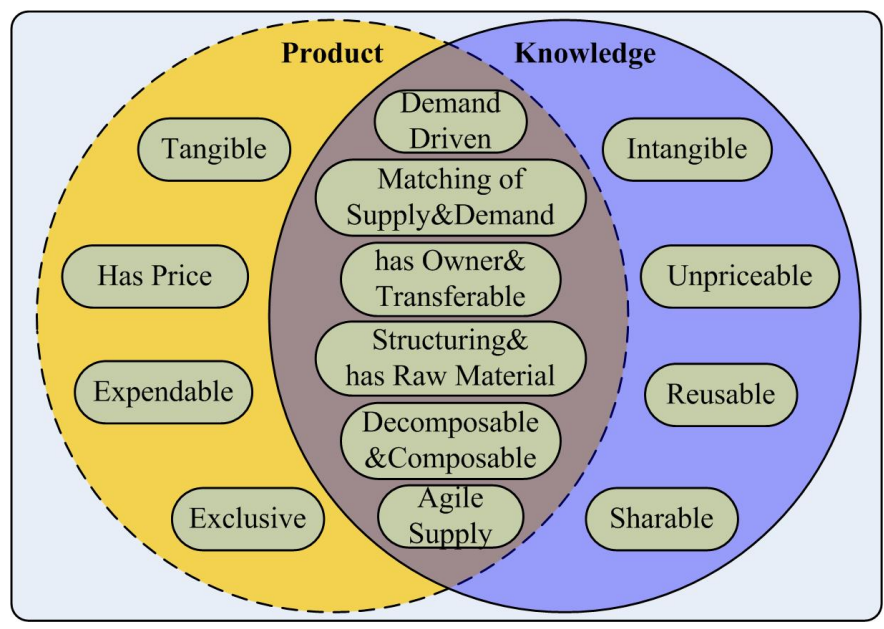

Fig. 3. Common Features of Knowledge and Products

Emergency decision-makers use EKP as reference to make appropriate decisions. Each decision is incorporated as an information source into subsequent decisions. Emergency decision-makers are either end-consumers or providers of raw materials.

\section{Agile Knowledge Supply Chain}

In the three knowledge requirements above we can see that emergency knowledge management is very similar to the ASC. The main characteristic of ASC which is distinct from the general Supply Chain is rapid reconstruction and readjustment with the formation and dissolution of a dynamic alliance. Agility of ASC is the ability of quick responses to survive, develop and enlarge the competitive advantages in an uncertain and rapid changing environment. Improved Supply Chain performance implies that a Supply Chain is capable of quickly responding to variations in customer demands with effective cost reduction, [20] such as lead time [21].

In emergency responses, alliances among various relevant organizations and departments (Emergency Alliances) are formed according to the different types of emergent incidents. Members of Emergency Alliances concentrate on their respective responsibilities, and establish organizational relationships based on integrative commands and cooperation. Emergency Alliances are special virtual enterprises and constitute Supply Chains based on knowledge management.

We construct Agile Knowledge Supply Chains (AKSC) to support emergency decision-making. They are directed toward the realization agility in decision-making support to reinforce emergency knowledge management. AKSC is a Supply Chain which takes knowledge as a product, establishes an Emergency Alliance, gives priority to its Command Center which directs Functional Departments, and has notable agility in emergency decision-making support. See the similarities between ASC and AKSC elements of reconstruction, information sharing and flow management in Table 1. 
Table 1. Similarity between ASC and AKSC

\begin{tabular}{|c|c|c|}
\hline Item & ASC & AKSC \\
\hline Reconstruction & $\begin{array}{l}\text { Rapid reconstruction and readjust- } \\
\text { ment according to market demand }\end{array}$ & $\begin{array}{l}\text { Rapid reconstruction and readjust- } \\
\text { ment according to emergent incident }\end{array}$ \\
\hline Information & Sharing information among enter- & Sharing information among the emer- \\
\hline Sharing & $\begin{array}{l}\text { prises in the Supply Chain to } \\
\text { avoid a bullwhip effect }\end{array}$ & $\begin{array}{l}\text { gency departments to avoid delays in } \\
\text { knowledge acquisition }\end{array}$ \\
\hline $\begin{array}{l}\text { Organizational } \\
\text { form }\end{array}$ & $\begin{array}{l}\text { Virtual enterprise, a dynamic } \\
\text { alliance based on the matching } \\
\text { supply and demand of products }\end{array}$ & $\begin{array}{l}\text { Emergency Alliance, a dynamic alli- } \\
\text { ance based on the matching supply } \\
\text { and demand of knowledge }\end{array}$ \\
\hline Drive Mode & Customer order-driven & Decision-maker requirement-driven \\
\hline Global Object & $\begin{array}{l}\text { Reduce the business risks arising } \\
\text { from uncertainty and variability }\end{array}$ & $\begin{array}{l}\text { Achieve ultimate effectiveness of } \\
\text { emergency decision implementation }\end{array}$ \\
\hline Output & Goods have commercial value & $\begin{array}{l}\text { All sorts of knowledge used in emer- } \\
\text { gency decision-making }\end{array}$ \\
\hline $\begin{array}{l}\text { Flow Manage- } \\
\text { ment }\end{array}$ & $\begin{array}{l}\text { Integrated flows of materials, } \\
\text { information, capital }\end{array}$ & $\begin{array}{l}\text { Integrated flows of knowledge de- } \\
\text { mands, supplies and production }\end{array}$ \\
\hline Agility & $\begin{array}{l}\text { Supply products to meet customer } \\
\text { demands in the shortest possible } \\
\text { time }\end{array}$ & $\begin{array}{l}\text { Supply knowledge to meet decision- } \\
\text { making demands in the shortest pos- } \\
\text { sible time }\end{array}$ \\
\hline Network & $\begin{array}{l}\text { Promote the circulation of prod- } \\
\text { uct, capital and information }\end{array}$ & $\begin{array}{l}\text { Facilitate knowledge re-use and } \\
\text { sharing }\end{array}$ \\
\hline
\end{tabular}

\section{Architecture of AKSC}

Generally, Emergency Alliances consist of Command Centers and functional departments. Emergency Alliances are usually established by Command Centers which bring together various emergency functional departments around the requirements of emergent incidents. So an Emergency Alliance has only one leader, its Command Center, which is usually launched and directed by a specific level of government. The relationships among the members of Emergency Alliances are, under unified leadership, directive, rather than the collaborative equality and mutual trust characteristic of traditional Supply Chains. Because of changing targets, requirements and tasks of emergent incidents the structure of an Emergency Alliance is dynamic. Members of Emergency Alliances, and the knowledge transferred among them, constitute the dynamic Supply Chain of emergency knowledge management.

Core technologies of the AKSC are knowledge decomposition, matching and integration, i.e. the reorganization of knowledge. It extends the knowledge management mode for emergency management from the traditional knowledge database to flowbased knowledge, from rule driven to product driven. AKSC also has excellent extendibility to accommodate changes in incidents and organizational structure. AKSC can integrate technologies of ontology, multi-agent, network, knowledge representation, reasoning, etc. Figure 4 shows the architecture of AKSC which mainly concerns the Command Center in the Emergency Alliance. 


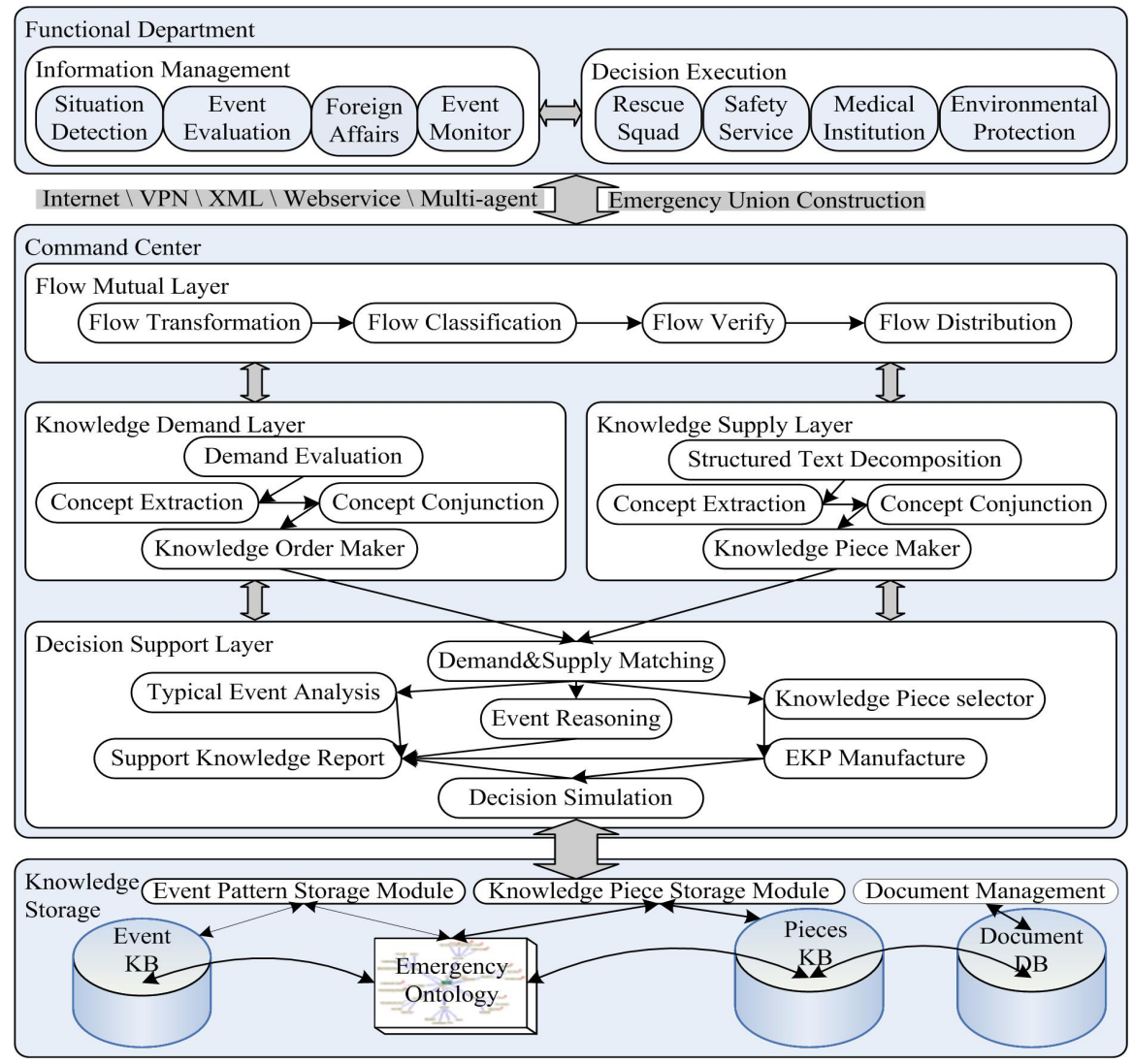

Fig. 4. Architecture of AKSC

\section{Conclusion}

This paper has analyzed three knowledge requirements for emergency decisionmaking: sources, agility and knowledge product features. We compared the knowledge management of emergency decision-making support with the Supply Chain management, a first in this paper, and regarded emergency knowledge as practical products. Using the operating mechanism of ASC for reference, we constructed the AKSC to support timely and effective decision-making through the quick acquisition of required knowledge. We briefly outline the definition, content and architecture of AKSC in this paper.

We believe the AKSC presented in this paper breaks new ground in knowledge management of the emergency decision-making support. However, some technical problems remain to be solved; such as methods of EKP design, approaches to demand description. We intend to dedicate ourselves to researching them. 


\section{Acknowledgement}

This research is supported by the Natural Science Foundation of China (Grant No, $70571011,70431001)$. The authors would like to express appreciation to the team of project EDKS for the sincere support.

\section{References}

1. Rong, L.L.: Reorganizing the Knowledge in Government Documents for Quick Response. KSS'2005. Laxenburg, Austria (2005)

2. Jia. X.N., Rong. L.L.: Classification Based Management Method for Government Documents in Emergency Response. KSS'2006. Beijing, China. (2006)

3. Hernandez, J.Z., Serrano, J.M.: Knowledge-based Models for Emergency Management Systems. Expert Systems with Applications, 20 (2001) 173-186

4. Mendonca, D., Rush, R., Wallace, W.A.: Timely Knowledge Elicitation from Geographically Separate, Mobile Experts during Emergency Response. Safety Science, 35 (2000) 193-208

5. Cortés, U., Sànchez-Marrè, M., Ceccaroni, L., R-Roda, I., Poch, M.: Artificial Intelligence and Environmental Decision Support Systems, Applied Intelligence, 13 (2000) 77-91

6. Yeh, T.H., Lo, J.G.: A Case Study of Knowledge-Based Expert System for Emergency Response of Chemical Spill and Fire. Environ. Inform. Arc. 2 (2004), 743-755

7. Liu, K.F.R.: Agent-based resource discovery architecture for environmental emergency management. Expert Systems with Applications, 27 (2004) 77-95

8. Viviane, B.D., Marcos, R.S.B., Jose, O.G., Jose, H.C.: Knowledge management support for collaborative emergency response. 9th CSCWD, Coventry, UK, (2005) 1188-1193

9. Lee, H.B., Kim, J.W., Park, S.J.: KWM: Knowledge-based Workflow Model for Agile Organization. Journal of Intelligent Information Systems, 13 (1999) 261-278

10. Melnik, G., Maurer, F.: Direct Verbal Communication as a Catalyst of Agile Knowledge Sharing. ADC'2004. Los Alamitos, CA. (2004)

11. Holz, H., Maus, H., Bernardi, A., Rostanin, O.: From Lightweight, Proactive Information Delivery to Business Process-Oriented Knowledge Management, Journal of Universal Knowledge Management 2 (2005) 101-127

12. Auer, S.: RapidOWL - an Agile Knowledge Engineering Methodology. STICA 2006, Manchester, UK. (2006)

13. Stojanovic, N., Mentza, G., Apostolou, D.: Semantic-enabled Agile Knowledge-based Egovernment. Http://www.imu.iccs.gr/sweg/papers/

14. Christopher, M.: The Agile Supply Chain: Competing in Volatile Markets. Industrial Marketing Management, 29 (2000) 37-44

15. Zhang, S.S., Gao, G.J.: Dynamic Allience and Agile Supply Chain. Computer Integration Manufacture System, 5 (1999) 1-5

16. Lou, P., Zhou, Z.D., Chen, Y.P., Ai, W.: Study on multi-agent-based Agile Supply Chain management. Int. J. Adv. Manuf. Tech. 23 (2004) 197-203

17. Stephanopoulos, G., Han, C.: Intelligent systems in process engineering: A review. Computers Chemical Engineering, 20 (1996) 743-791

18. Wang, Z.T.: Knowledge System Engineering. Beijing: Science Publishing Company, 2004

19. Sigel, A.: Topic Maps in Knowledge Organization. http://index.bonn.iz-soz.de/ sigel/

20. Agarwal, A., Shankar, R., Tiwari, M. K.: Modeling the Metrics of Lean, Agile and Leagile Supply Chain: An ANP-based Approach. Eur. J. Oper. Res., 173 (2006) 211-225

21. Mason-Jones, R., Towill, D.R.: Total Cycle Time Compression and the Agile Supply Chain. European Journal of Operational Research, 159 (2004) 379-392 